\title{
G. BACHELARD E W. HEISENBERG: O PROBLEMA DA LINGUAGEM NA MECÂNICA QUÂNTICA
}

\author{
David Velanes ${ }^{1}$ \\ Universidade Federal da Bahia (UFBA) \\ (iD) https://orcid.org/0000-0002-8992-6701 \\ E-mail: dvelanes@gmail.com
}

\section{RESUMO:}

A mecânica quântica instituiu uma linguagem matemática inteiramente inédita. Essa mudança na física exigiu que físicos e filósofos repensassem os conceitos pelos quais se podiam representar a realidade, uma vez que as noções clássicas se revelaram limitadas na compreensão dos fenômenos atômicos. O filósofo francês G. Bachelard e o físico alemão W. Heisenberg são autores que discorreram acerca das grandes modificações que ocorreram no seio da física, e, com isso, trataram do problema da linguagem na mecânica quântica. Neste artigo, o objetivo é recorrer aos argumentos de ambos os autores para evidenciar relações entre suas ideias acerca da temática referida. Destaca-se que Bachelard e Heisenberg criticam a aplicação da linguagem usual e dos conceitos filosóficos da modernidade na nova física, mas, mediante sua noção de ruptura, o filósofo francês propõe que a mecânica quântica se restrinja à linguagem matemática. Ideia esta que vai contra ao princípio de complementaridade de Bohr, admitido por Heisenberg na compreensão dos fenômenos quânticos e para uma interpretação da física quântica.

PALAVRAS-CHAVE: Epistemologia; Bachelard; Heisenberg; Linguagem; Mecânica quântica.

\section{G. BACHELARD AND W. HEISENBERG: THE PROBLEM OF LANGUAGE IN QUANTUM MECHANICS}

\begin{abstract}
:
The quantum mechanics instituted a completely new mathematical language. This change in physics required physicists and philosophers to rethink the concepts by which reality could be represented, since classical notions were limited in the understanding of atomic phenomena. The French philosopher G. Bachelard and the German physicist W. Heisenberg are authors who have discussed the major changes that have occurred in physics and have dealt with the problem of language in quantum mechanics. In this article, the objective is to resort to the arguments of both authors to evidence relations between their ideas about the referred subject. It is noteworthy that Bachelard and Heisenberg criticize the application of the usual language and philosophical concepts of modernity in the new physics, but, through his notion of rupture, the French philosopher proposes that quantum mechanics be restricted to mathematical language. This idea runs counter to Bohr's principle of complementarity, which Heisenberg acknowledges in the understanding of quantum phenomena and an interpretation of quantum physics.
\end{abstract}

KEYWORDS: Epistemology; Bachelard; Heisenberg; Language; Quantum mechanics.

${ }^{1}$ Doutorando em Filosofia na Universidade Federal da Bahia (UFBA), Salvador - BA, Brasil.

VELANES, David. G. Bachelard e W. Heisenberg: o problema da linguagem na mecânica quântica. Griot : Revista de Filosofia, Amargosa - BA, v.19, n.3, p.33-45, outubro, 2019. 


\section{Introdução}

O advento da mecânica quântica, na primeira metade do século passado, pôs em questão os limites de aplicação dos conceitos da física clássica, que eram tomados como incontestáveis. As modificações que foram instituídas no seio da física, na época contemporânea, estabeleceram uma verdadeira ruptura com o pensamento científico e filosófico da modernidade, à medida que a teoria da relatividade e a teoria quântica introduziram métodos e objetos do conhecimento inteiramente novos na história.

Filósofos e cientistas foram obrigados a repensar as ideias perante a renovação epistêmica ocorrida no século XX. Gaston Bachelard (1884-1962), que pode ser considerado como um autêntico filósofo da mecânica quântica, e Werner Heisenberg (1901-1976), um dos físicos fundadores desse novo setor da física, são autores que refletiram sobre os problemas apresentados pela nova ciência. Uma dessas questões diz respeito à linguagem científica, que pretendemos tratar neste trabalho.

Gaston Bachelard foi um filósofo francês que edificou sua epistemologia a partir das revoluções ocorridas na primeira metade do século passado. A filosofia científica bachelardiana inseriu, especialmente na França, uma nova forma de se olhar a história das ciências, tendo influenciado diversos filósofos como G. Canguilhem (1904-1995)² e M. Foucault (1926-1984)². É possível afirmar, sem dúvidas, que as noções bachelardianas de ruptura, recorrência histórica, fenomenotécnica e obstáculos epistemológicos, por exemplo, apresentam-se como inteiramente originais na epistemologia contemporânea.

Werner Heisenberg foi um físico alemão cujas contribuições foram fundamentais para a emergência da mecânica quântica. Uma delas é conhecida como princípio de incerteza, no qual reforçou o aspecto indeterminístico na nova física. Junto às concepções do físico dinamarquês $\mathrm{N}$. Bohr (1885-1962), entre outros, as ideias de Heisenberg constituíram em importantes contribuições para a compreensão da situação da física contemporânea. Compreensões sobre as quais se edificou o que ficou conhecida como "Intepretação de Copenhague" ou "Interpretação Ortodoxa".

O objetivo deste artigo é estabelecer algumas relações entre as ideias do filósofo francês e as do físico alemão acerca do problema da linguagem na mecânica quântica. Para tanto, uma vez que o pensamento de Bachelard é assistemático, daremos uma atenção maior há algumas de suas obras epistemológicas, a saber, Le nouvel esprit scientifique (1934) e L'activité rationaliste de la physique contemporaine (1951). Em Heisenberg, tomaremos como fio condutor sua obra Physics and philosophy, the revolution in modern science (1958).

A escolha dos dois autores não foi aleatória. A relação entre as ideias de Bachelard e de Heisenberg têm sido um tema ainda pouco abordado no campo da filosofia das ciências atualmente. Na epistemologia bachelardiana, é possível constatar uma apropriação, por vezes direta e por vezes indireta das ideias de Heisenberg, sendo este autor bastante citado pelo filósofo francês em suas obras.

É instrutivo esclarecer que as ideias de Bachelard constituem uma rigorosa reflexão filosófica, pela qual emerge uma filosofia científica original. Heisenberg, como cientista, embora tenha elaborado diversas reflexões epistemológicas em suas obras, suas ideias, a nosso ver, não constituem uma filosofia propriamente dita. Investigar o campo de pressupostos filosóficos das

\footnotetext{
${ }^{2}$ Cf. G. Canguilhem, em Études d'histoire et de philosophie des sciences (1968). Introdução: "L'objet de l'histoire des sciences", e parte II: "L'histoire de la science dans le travail épistémologique de Gaston Bachelard", "Gaston Bachelard et les philosophes" e "Dialectique et philosophie du non chez Gaston Bachelard".

${ }^{3}$ Cf. M. Foucault, em L'archéologie du savoir (1969), p. 4; 223.
}

VELANES, David. G. Bachelard e W. Heisenberg: o problema da linguagem na mecânica quântica. Griot : Revista de Filosofia, 
argumentações do físico alemão se trata de uma tarefa relevante, mas que não é o foco deste trabalho, embora acreditemos que alguma luz aqui possa ser lançada. ${ }^{4}$

\section{A mecânica quântica como ruptura epistêmica}

Segundo Bachelard (1963), “as ciências físicas e químicas, em seu desenvolvimento contemporâneo, podem ser caracterizadas epistemologicamente, como domínios de pensamento que romperam nitidamente com o conhecimento vulgar" (p.102). Correlativamente, Heisenberg (2007) ressalta que foi por meio da teoria quântica que se evidenciaram as "mudanças mais fundamentais com relação ao conceito de realidade, e é na forma final dessa teoria que as novas ideias da física moderna se concentraram e se cristalizaram" (p. 33). No mesmo parágrafo dessa citação, o autor ainda é categórico ao afirmar que: "a mudança no conceito de realidade que se manifesta na teoria dos quanta não é uma simples continuação do passado, parece ser uma verdadeira ruptura na estrutura da ciência moderna" (p. 33).

Essas citações de Bachelard e Heisenberg têm o sentido de destacar que as ciências contemporâneas entraram em um novo campo epistêmico, cuja característica fundamental é o pensamento matemático como base de toda experiência, que deu às ciências um grau de complexidade muito maior em relação ao espírito científico até meados do século XIX. O pensamento matemático, o qual Bachelard se refere, é o próprio formalismo matemático da mecânica quântica, que, segundo Heisenberg (2007), adquiriu coerência na segunda década do século passado, por meio de duas vias, quais sejam, o princípio de complementaridade de Bohr e a equação de Schrödinger.

Segundo Bachelard (1999), o espírito científico contemporâneo apresenta uma inversão do vetor epistemológico, isto é, o ponto de partida deixa de ser o real imediato cedendo lugar ao pensamento racional, no que diz respeito à construção do objeto científico. Esta perspectiva operada especialmente pela mecânica quântica causou uma revolução no saber, uma vez que instituiu uma nova ordem de fenômenos que não podem ser considerados como dados do mundo natural. Esses fenômenos possuem características inteiramente distintas em relação ao objeto do mundo comum ao qual se debruçava a física clássica.

Bachelard (1999) e Heisenberg (2007) enfatizam que a mecânica de Newton se apresentou, no século XVII, como um sistema perfeito e absoluto, configurado por meio de uma grande coerência matemática, pela qual se podia representar a realidade de forma satisfatoriamente objetiva. Heisenberg (2007) explica que:

Newton começa seu Principia com uma série de definições e axiomas que estão interligados de tal forma que eles constituem o que podemos chamar de "sistema fechado" [...] a imagem matemática do sistema assegura que nele não pode ter contradições (p. 85).

Assim como o físico alemão, Bachelard (1999) afirma que, até o século XX, "vivíamos no mundo newtoniano como em uma residência espaçosa e clara. $O$ pensamento newtoniano era à primeira vista um tipo maravilhosamente límpido do pensamento fechado; dele não se podia sair a não ser por arrombamento" (p. 46).

Pode-se dizer que tal fechamento matemático do sistema newtoniano configura uma importante característica para compreender como a mecânica quântica abalou seus princípios mais fundamentais. ${ }^{5}$

\footnotetext{
${ }^{4}$ Pode-se conferir o artigo de Leite e Simon (2010), intitulado "Werner Heisenberg e a Interpretação de Copenhague: a filosofia platônica e a consolidação da teoria quântica".
}

VELANES, David. G. Bachelard e W. Heisenberg: o problema da linguagem na mecânica quântica. Griot : Revista de Filosofia, 
A epistemologia bachelardiana apresenta a ideia segundo a qual a mecânica quântica estabelece uma ruptura total com as noções da física clássica, que tomava como base a vida cotidiana. Velanes (2018), ao comentar as ideias do filósofo francês, explica que "o mundo oculto revelado pela mecânica quântica em nada se aproxima com o mundo da vida comum estudado pela mecânica clássica" (p.143). Para Bachelard (1965; 1963), a nova física trabalha na realização de objetos do pensamento por meio de refinados instrumentos técnicos de medição e se afasta radicalmente dos fenômenos do mundo natural, instituindo uma "segunda natureza".

De modo semelhante a Bachelard, Heisenberg (2007) mostra que as profundas modificações que ocorreram na física contemporânea instituíram um grande afastamento das noções comuns da física clássica. Para o físico alemão, os conceitos da física newtoniana não passam de um refinamento das noções da vida ordinária. Os conceitos de espaço, tempo, matéria, causalidade, entre outros, foram afetados pela teoria da relatividade especial e pela emergência da teoria quântica, pondo em cheque os limites de aplicação dessas noções.

Ao inaugurar a noção de ruptura epistemológica, que é uma das teses centrais de seu pensamento, Bachelard $(1993 ; 1966 ; 1965)$ afirma que as ciências modernas e positivistas sofreram um abalo perante a teoria quântica, uma vez que aquelas ciências tinham como base o real imediato, fundamentadas no sensualismo. Heisenberg (2007), por sua vez, explica que o século XIX ainda apresentava um sistema bastante rígido para a física, baseado nos conceitos da modernidade, e pela ideia de que a explicação do real deveria se basear nos dados empíricos, isto é, perceptíveis por meio dos sentidos humanos ou que pudessem ser observados mediante os aparelhos científicos.

É no sentido supracitado que os objetos estudados pela física clássica possuem como marca a substancialização, na qual se pode determinar especificamente sua existência real como dado geometricamente sensível. Diferentemente, os objetos quânticos, como originais na história, apresentam uma dessubstancialização na concepção de fenômeno, ferem os princípios da geometria euclidiana e da lógica clássica, tal como os próprios métodos de investigação então existentes na física (Bachelard, 1999; 1996; 1975; 1965).

As considerações de Heisenberg $(2007 ; 1954)$ acerca da situação dos objetos quânticos se assemelham com as ideias de Bachelard, à medida que o físico critica as concepções materialistas na compreensão da noção de átomo, que se iniciou no pensamento grego antigo por meio das ideias de Leucipo e Demócrito e perdurou até o século XIX. Segundo Heisenberg (2007; 1954), nenhuma concepção materialista (ou substancializada) pode ser introduzida para compreender os fenômenos quânticos, uma vez que as investigações experimentais demonstraram que esses objetos, como totalmente inéditos na história, são muito mais abstratos, formas matemáticas, pelas quais se tornam mais consistentes as explicações da realidade. ${ }^{6}$

\footnotetext{
${ }^{5}$ Com mais um intuito de distinguir a nova física da física clássica, Heisenberg (2007) destaca que "as equações do movimento da mecânica de Newton foram substituídas por equações semelhantes entre matrizes. Foi uma experiência estranha ver como muitos dos resultados da mecânica antiga, como conservação de energia, etc., também poderiam ser encontrados no novo esquema. Mais tarde, as investigações de Born, Jordan e Dirac mostraram que as matrizes que representam a posição e a quantidade de movimento do elétron, não podem ser trocadas. Este último fato demonstra claramente a diferença essencial entre mecânica quântica e mecânica clássica" (p.41).

${ }^{6}$ Heisenberg (2007) diz que: As partículas elementares não são, a propósito, unidades de matéria eterna e indestrutível, pelo contrário, podem ser transformados em outras. Na verdade, se duas dessas partículas, movendo-se no espaço em alta energia cinética, colidem, da energia disponível, muitas novas partículas elementares podem ser criadas, e as antigas partículas podem desaparecer na colisão. Esses fatos foram observados com frequência e oferecem provas convincentes de que todas as partículas são feitas da mesma substância: energia (p. 67-68). Para ampliar a leitura acerca da história do conceito de átomo pode-se conferir o capítulo "Quantun theory and the roots of atomic science", da obra de Heisenberg, Physics and philosophy, the revolution in modern science e a obras de Bachelard L'activité rationaliste de la physique contemporaine, capítulo III, "La notion de corpuscule dans la science contemporaine" e obra Les intuitions atomistiques.
}

VELANES, David. G. Bachelard e W. Heisenberg: o problema da linguagem na mecânica quântica. Griot : Revista de Filosofia, Amargosa - BA, v.19, n.3, p.33-45, outubro, 2019. 
As análises de Bachelard e Heisenberg dizem que as peculiaridades dos objetos quânticos, que rompem com o saber vulgar, devem constituir mudanças radicais em torno do arcabouço teórico das ciências e da filosofia para que se possa compreendê-los de forma inambígua.

São importantes as considerações supracitadas acerca da ruptura instituída pela mecânica quântica para esclarecer o ponto de partida da questão da linguagem científica na nova física. Podemos dizer que é por meio da ruptura do saber científico com o senso comum que repousa tal questão, pois, a física newtoniana, para expressar suas leis, à medida que se encontra ligada com o conhecimento vulgar, recorre às noções que se derivam da experiência ordinária, e a física quântica, diferentemente do sistema de Newton, estabeleceu a linguagem simbólica da matemática como a forma mais objetiva de se compreender os fenômenos atômicos.

Na mesma linha de esclarecimento é possível lançar mão das palavras do físico M. Planck quando diz em sua conferência, $O$ conceito de causalidade na física ${ }^{7}$, que:

[...] basta uma olhada rápida para constatar como a imagem do mundo construída pela física quântica se afasta do mundo dos sentidos. Também se pode ver como se tornou mais difícil traduzir para a linguagem da física clássica um evento expresso na linguagem quântica e vice-versa (PLANCK, 2012, p. 50).

Bachelard e Heisenberg explicam a revolução na física, no século XX, como uma ruptura epistêmica, mas embora o termo "ruptura" apareça em alguns argumentos do físico alemão, o sentido dessa noção se revela muito mais profunda nas ideias do filósofo francês, isto é, como um conceito filosófico complexo, constitutivo de sua filosofia científica. Nas ideias de Heisenberg, entendemos que o termo "ruptura" deve ser compreendido mais no sentido comum do que propriamente filosófico. Entretanto, apesar das diferenças de uso do termo, ambos os autores não deixam de reconhecer que a profunda revolução epistêmica operada na física contemporânea constitui um ponto paradigmático de renovação das ideias científicas e filosóficas.

\section{Linguagem usual e linguagem matemática}

Segundo Heisenberg (2007), na física clássica, para que ocorra a compreensão dos fenômenos, é preciso relacionar os fatos ou resultados dos experimentos com símbolos matemáticos. Os símbolos recebem nomeações, e, dessa forma, vinculam-se à linguagem. Logo, os símbolos matemáticos formam um conjunto coerente de definições e axiomas, pelos quais, por meio de equações matemáticas, podem representar as leis da natureza. Foi dessa forma que a física clássica podia descrever objetivamente as leis naturais mediante a linguagem usual, à medida que os experimentos, que se baseavam em observações imediatas, podiam ser descritos por meio desse tipo de linguagem.

Bachelard (1999) e Heisenberg (2007) são unanimes ao enfatizarem que o século XX apresentou uma verdadeira perturbação nesse esquema harmonioso da física clássica, pois a nova física introduziu métodos originais para abordar os novos fenômenos, onde se alteraram diversos conceitos pelos quais a linguagem usual podia se ligar diretamente à linguagem matemática.

Para Heisenberg (2007), na evolução do saber, a linguagem científica adquire expansão em relação às significações dos conceitos, tal como a criação de novas noções. "Aparecem novos termos e os velhos se aplicam a um campo mais amplo ou diferente da linguagem comum.

${ }^{7}$ Cf. M. Planck (2012, p. 41-58).

VELANES, David. G. Bachelard e W. Heisenberg: o problema da linguagem na mecânica quântica. Griot : Revista de Filosofia, 
Termos tais como "energia", "eletricidade", "entropia", constituem exemplos correntes" (p. $149)$.

Assim como Bachelard (1963), Heisenberg (2007) reconhece que o século XX evidenciou que nem sempre a linguagem científica pode ser compreendida como uma extensão da linguagem comum, passível de se ajustar às inovações das ciências. A ligação harmoniosa clássica entre os conceitos comuns e os símbolos matemáticos se viu abalada pelo advento da teoria da relatividade especial e pela teoria quântica. Conceitos clássicos como os de espaço e tempo foram ressignificados pelas novas mecânicas.

Bachelard (2014; 1999) e Heisenberg (2007) esclarecem que a base geométrica da teoria da relatividade é constituída por uma estrutura complexa com quatro dimensões, na qual o espaço e o tempo se encontram intrinsecamente relacionados. Dessa forma, a base geométrica da mecânica de Einstein rompe com o espaço tridimensional da geometria euclidiana, que fundamenta a física de Newton. A mecânica quântica, em ruptura com a mecânica clássica, trabalha com o "espaço conceitual", com o "espaço de configuração", no qual coexistem diversas dimensões referentes às coordenadas dos objetos quânticos. Em outras palavras, os conceitos clássicos de espaço e tempo se revelaram inaptos para abordar a nova situação da física. $^{8}$

O físico alemão ainda ressalta que:

Na teoria da relatividade geral, a linguagem pela qual descrevemos as leis gerais realmente concorda com a linguagem matemática dos matemáticos e, para a descrição dos próprios experimentos, podemos usar os conceitos comuns, uma vez que a geometria euclidiana é válida com precisão suficiente em pequenas dimensões. No entanto, o problema mais difícil, em relação ao uso da linguagem, é colocado pela teoria quântica. Aqui nos falta, em princípio, um guia simples para correlacionar os símbolos matemáticos com os conceitos da linguagem comum; e a única coisa que sabemos desde o início é o fato de que nossos conceitos comuns não podem ser aplicados à estrutura dos átomos. (HEISENBERG, 2007, p. 153).

Emerge, na física contemporânea, uma dualidade em relação à linguagem, a saber, a linguagem estritamente simbólica da matemática e a linguagem usual da física clássica. Esta última é denunciada por Bachelard (1963) e Heisenberg (2007) como inadequada conceitualmente para explicar os novos fenômenos. Afirma o físico alemão que "o progresso da técnica experimental de nosso tempo traz ao âmbito da ciência aspectos da natureza que não podem ser descritos com os termos dos conceitos comuns" (p. 129).

Qual seria a linguagem mais adequada para descrever os novos fenômenos? Como descrever de forma inambígua os fenômenos atômicos, se estes, em suas características mais fundamentais, ultrapassam os limites do arcabouço conceitual então existente? É possível falar da estrutura dos átomos por meio da linguagem usual?

Como destacamos acima, Bachelard e Heisenberg oferecem uma resposta negativa para tais questões, que é a ideia segundo a qual a linguagem usual é inapta para descrever objetivamente os fenômenos atômicos. Mas, embora ofereçam uma resposta semelhante, ambos os autores elaboram propostas epistemológicas diferentes para tentar solucionar o problema na física quântica entre linguagem usual e linguagem matemática.

Ambos os autores concordam que, para os físicos, bastaria a linguagem matemática, os esquemas matemáticos, para uma compreensão objetiva dos resultados dos experimentos. No entanto, para Heisenberg (2007), ao seguir as ideias de N. Bohr, as ciências precisam comunicar

\footnotetext{
${ }^{8}$ Os dois autores também oferecem o exemplo do conceito de temperatura para demonstrar como as noções clássicas se tornaram insuficientes com o advento da mecânica quântica. Cf. Bachelard (1963, p. 216) e Heisenberg (2007, p. 155).
}

VELANES, David. G. Bachelard e W. Heisenberg: o problema da linguagem na mecânica quântica. Griot : Revista de Filosofia, Amargosa-BA, v.19, n.3, p.33-45, outubro, 2019. 
seus resultados para aqueles que não são físicos. É preciso socializar o conhecimento científico tornando a linguagem simbólica clara para todos.

Segundo Heisenberg (2007), é preciso ter consciência de que os conceitos clássicos possuem uma aplicação bastante limitada e, em determinados casos, quando as dificuldades são grandes, deve-se abrir mão da linguagem usual, do arcabouço conceitual clássico, e se manter apenas dentro dos esquemas matemáticos, pois estes estabelecem uma correlação clara e objetiva com os fatos experimentais. Apenas mediante a linguagem simbólica da matemática se pode falar de modo inteiramente objetivo os fenômenos atômicos da física contemporânea.

Heisenberg aceita o princípio de complementaridade de Bohr, embora não deixe de reconhecer que o emprego dos conceitos clássicos, nas descrições dos fenômenos quânticos, sempre abre uma margem ambígua que pode levar a contradições. $O$ físico alemão diz que:

Este uso da linguagem é, em muitos aspectos, muito satisfatório, uma vez que nos lembra do uso similar da linguagem na vida cotidiana ou na poesia. Verificamos que a situação de complementaridade não se limita apenas ao mundo atômico. Descobrimos quando refletimos sobre uma decisão e as razões de nossa decisão ou quando temos que escolher entre o prazer da música ou a análise de sua estrutura. Por outro lado, quando os conceitos clássicos são empregados dessa maneira, eles sempre mantêm certa imprecisão; eles apenas adquirem em sua relação com a "realidade" a mesma significância estatística que os conceitos da termodinâmica clássica em sua interpretação estatística. (HEISENBERG, 2007, p. 155).

O princípio de complementaridade (ou princípio de correspondência), de Bohr, buscou solucionar o problema entre linguagem matemática e linguagem usual na física quântica. Esse princípio diz que as descrições dos fenômenos quânticos devem ser estabelecidas dentro do arcabouço conceitual da física clássica. Deste modo, de acordo com Bohr, as duas linguagens (física clássica e física quântica) devem ser compreendidas como complementares. Bohr (1995), em seu texto $O$ debate com Einstein sobre problemas epistemológicos na física atômica ${ }^{9}$, esclarece seu ponto de vista da "complementaridade", que, segundo ele,

[...] é próprio para abranger os traços característicos de individualidade dos fenômenos quânticos e, ao mesmo tempo, esclarecer os aspectos peculiares do problema observacional nesse campo da experiência. Para esse fim, é decisivo reconhecer que, por mais que os fenômenos transcendam o âmbito da explicação física clássica, a descrição de todos os dados deve ser expressa em termos clássicos (p. 50).

A solução oferecida por Bohr (princípio de complementaridade) acerca do problema da linguagem na mecânica quântica (problema apontado também por Bachelard e Heisenberg, entre outros) constitui como parte integrante da "Interpretação de Copenhague" ou "Interpretação Ortodoxa" da teoria quântica. Heisenberg (2007), explica que "(...) a Intepretação de Copenhague considera as coisas e os processos que podem ser descritos em termos de conceitos clássicos, isto é, o real como fundamento de qualquer interpretação física" (p. 127). ${ }^{10}$

Heisenberg e Bohr são os principais autores que instituíram os fundamentos e difundiram essa forma de interpretação da teoria quântica, que toma como princípios fundamentais, o princípio de complementaridade e a ideia de uma física indeterminista. Cassidy

${ }^{9}$ Cf. N. Bohr (1995, p. 41-84).

10 É possível conferir Heisenberg (2007), nos capítulos III e VIII: "A Copenhagen Interpretation of quantun theory" e "Criticism and counter-proposals to the Copenhagen Interpretation of quantun theory", respectivamente, para uma maior compreensão do que foi a "Interpretação de Copenhague" e outras interpretações da mecânica quântica na primeira metade do século XX.

VELANES, David. G. Bachelard e W. Heisenberg: o problema da linguagem na mecânica quântica. Griot : Revista de Filosofia, Amargosa - BA, v.19, n.3, p.33-45, outubro, 2019. 
(1991) ressalta que um dos objetivos das obras do físico alemão, como aquela intitulada The physical principles of quantum mechanics (1949), era propagar as ideias acerca da mecânica quântica expressas nos encontros em Copenhague. Ideias das quais são advindas grande parte das reflexões de Bohr. ${ }^{11}$

No que toca à questão do objeto deste trabalho, que é discutir o problema da linguagem na física quântica a partir das ideias de Bachelard e Heisenberg, podemos perguntar: a noção de "complementaridade", como elemento constitutivo da "Interpretação de Copenhague", é aceita por Bachelard?

É importante destacar que, nas obras epistemológicas bachelardianas, não são feitas referências ao princípio de complementaridade de Bohr. Não podemos deixar de acusar Bachelard acerca de tal omissão, uma vez que sua filosofia é elaborada no mesmo contexto no qual emergem as ideias discutidas nos encontros em Copenhague, onde Bohr exercia uma notável influência, e, além disso, muitas das ideias que surgem naquelas conferências são absorvidas pelo filósofo do novo espírito científico, especialmente por intermédio do físico francês Louis de Broglie (1892-1987), conforme explica Freire Jr (2010). Nas obras bachelardianas também são feitas diversas referências ao físico dinamarquês. ${ }^{12}$

Por que Bachelard teria omitido o princípio de Bohr em suas análises? Apresentamos uma hipótese, a saber, de que o princípio de complementaridade, aceito por Heisenberg, entra em contradição com a noção de ruptura epistemológica bachelardiana.

Ao radicalizar sua noção de ruptura, Bachelard enfatiza o desprendimento total entre linguagem usual e linguagem matemática. Para o filósofo francês, transplantar os conceitos comuns para o âmbito do saber científico contemporâneo, que é fundamentado nos símbolos matemáticos, seria criar obstáculos ao conhecimento objetivo.

Por meio da noção de ruptura, Bachelard $(1986 ; 1966)$ faz uma distinção entre conceito científico e conceito vulgar. "O conceito empírico é conceito de classificação, o conceito racional é conceito de interconexões, de relações absolutamente recíprocas" (p. 169). O conceito vulgar ou empírico é expresso pela linguagem usual, a linguagem da vida ordinária, e, nesse sentido, encontra-se ligado ao senso comum. Já os conceitos científicos são operatórios, dinâmicos, expressos pela álgebra e pertencem ao novo espírito científico das ciências.

Segundo Bachelard $(1986 ; 1965 ; 1963)$, se ocorreu uma ruptura entre senso comum e saber científico, na época contemporânea, então há uma revolução na ordem dos conceitos. Os conceitos são fontes que reforçam a ruptura instaurada entre física clássica e física quântica. Por exemplo, a noção de espaço na teoria quântica não pode ser interpretada no sentido da física newtoniana.

Conforme a epistemologia bachelardiana, estabelece-se, na renovação da episteme no século XX, atualizações conceituais por meio de retificações discursivas das noções, que torna possível que esses conceitos possam representar as experiências inéditas e impossíveis para um sistema teórico do passado como o de Newton. Ao explicar a questão do dinamismo conceitual na epistemologia de Bachelard, Velanes (2018) esclarece que:

Os conceitos são redes de relações que possuem a capacidade de renovação sobre as experiências atuais. A renovação conceitual é necessária diante de novas experiências para cooperar na construção de novos conhecimentos (p. 57). 11 Pode-se conferir também o texto de Heisenberg (1995), "The development of the interpretation of the quantum theory".
12 Cf. G. Bachelard (1965, p. 69-70; 1963, p. 216; 1996, p. 138-139).

VELANES, David. G. Bachelard e W. Heisenberg: o problema da linguagem na mecânica quântica. Griot : Revista de Filosofia, 
Os conceitos vulgares, à medida que se encontram ligados ao saber comum, mediante a linguagem usual, podem apresentar ligações implícitas e inconscientes com valores subjetivos criando obstáculos ao conhecimento objetivo, desde que aplicados às ciências contemporâneas, uma vez que estas se fundamentam no simbolismo matemático.

Segundo Bachelard (1965), os conceitos da linguagem usual atrapalham a compreensão dos conceitos científicos, pois o sentido das noções comuns tende a se cristalizar no movimento histórico do saber. Assim, os conceitos da linguagem comum se tornam absolutamente limitados para descrever os resultados experimentais da mecânica quântica. Conforme Bachelard (1966), a objetividade do saber científico deve se pautar dentro dos conceitos operatórios. Esses conceitos, que são rede de relações entre os símbolos matemáticos, afastam as interpretações ambíguas, enquanto os conceitos da linguagem comum, ao se relacionarem com imagens e analogias, criam perturbações no conhecimento.

Bachelard não aceita nenhuma correlação entre a linguagem usual e a linguagem matemática, o que o leva a criticar o ensino de ciências no qual toma como ponto de partida os conceitos mais elementares e fazem analogias com fatos da vida cotidiana. Na concepção do autor, os conceitos da linguagem usual podem atrapalhar o verdadeiro aprendizado de uma teoria científica.

Em suma, é possível dizer que, no pensamento do filósofo francês, a solução da questão expressa por Heisenberg e Bohr acerca da linguagem (de como tornar clara a todos o seres humanos os resultados dos experimentos em física quântica) é restringir as explicações ao uso da linguagem matemática, abdicando radicalmente da linguagem usual, enquanto o físico alemão, ao aceitar o princípio de complementaridade, compreende a necessidade de transplantar as noções do passado para tornar compreensíveis os resultados dos experimentos em física quântica.

O princípio de complementaridade e as relações de incerteza constituem dois elementos importantes da "Interpretação Ortodoxa", conforme Heisenberg (2007) e Bohr (1995). Deste modo, não podemos concordar com a afirmação de Guimarães (2018) quando diz que a "Interpretação de Copenhague" é adotada por Bachelard. Consideramos tal afirmação parcialmente verdadeira, à medida que, como explica bem o autor, o filósofo francês admite o princípio de incerteza como fundamento de uma física indeterminista, em ruptura com a base determinista da ciência moderna, e que vai caracterizar um dos aspectos do novo espírito científico. Entretanto, como visto acima, a "Interpretação de Copenhague" não toma somente em consideração as relações de incerteza de Heisenberg, mas também o princípio de complementaridade de Bohr. Princípio com o qual Bachelard não se compromete em sua analise epistemológica da mecânica quântica e que Guimarães (2018) não considerou ao fazer tal afirmação.

\section{A linguagem filosófica}

Embora as ideias apresentada por Bachelard e Heisenberg ao problema da linguagem na mecânica quântica sejam diferentes, há, além da concepção de que a física quântica revoluciona as bases da física, outro ponto em comum. Os dois autores, em função das grandes modificações que ocorrerem na física no século $\mathrm{XX}$, instituem sérias críticas a alguns sistemas filosóficos da modernidade como o de Descartes e Kant. ${ }^{13}$

\footnotetext{
13 Em Bachelard, as críticas instituídas à epistemologia cartesiana estão sistematizadas especialmente na obra Le nouvel esprit scientifique, capítulo "L'épistémologie non-cartésienne". O mesmo não ocorre com as críticas à filosofia kantiana, uma vez que estão distribuídas entre as obras bachelardianas. No entanto, ainda de forma assistemática, é possível conferir a obra La philosophie $d u$ Non, na qual o autor tece diversas considerações contra a teoria do conhecimento de Kant. No caso de Heisenberg, para uma melhor compreensão de suas críticas aos dois filósofos modernos, pode-se conferir a obra Physics and
}

VELANES, David. G. Bachelard e W. Heisenberg: o problema da linguagem na mecânica quântica. Griot : Revista de Filosofia, Amargosa - BA, v.19, n.3, p.33-45, outubro, 2019. 
Acerca da filosofia cartesiana é especialmente o método que é problematizado por Bachelard, uma vez que, segundo ele, em sua obra Le nouvel esprit scientifique, a regras metodológicas cartesiana teriam se tornadas obsoletas diante dos novos métodos instituídos pela física quântica, que possui um maior grau de complexidade em relação à física newtoniana.

Segundo Bachelard (1999), as ideias de evidência, simplicidade e análise já não possuem fecundidade aplicativa perante os novos fenômenos físicos. O objeto científico é mutável, portanto, os métodos devem acompanhar as modificações que aparecem nas técnicas experimentais. Além disso, por se tratar de um método redutivo, a aplicação da metodologia cartesiana aos fenômenos atômicos tende ignorar a complexidade desses objetos causando erros. $^{14}$

Heisenberg (2007) denuncia que a separação estabelecida pelo racionalismo cartesiano entre os conceitos de res extensa e res cogitans, ou seja, o campo material e o campo do pensamento, estabeleceu a separação moderna entre sujeito e objeto, distinção esta que, para o autor, já não pode se aplicar à mecânica quântica, uma vez que não é possível separar o sujeito que descreve e interpreta os fenômenos quânticos dos aparelhos técnicos de medição e do mundo.

A atividade da física contemporânea já não é somente descrever e explicar simplesmente os fenômenos por meio de sua aparelhagem técnica (Bachelard, 1965; 1999; Heisenberg, 2007). No trabalho científico da mecânica quântica ocorre uma interação entre o mundo e o sujeito do conhecimento. Deste modo, a natureza é descrita tal como se revela pela maneira com a qual o sujeito a questiona. "Esta é uma possibilidade que Descartes não poderia ter pensado; mas faz que a separação nítida entre o mundo e o eu seja impossível" (HEISENBERG, 2007, p. 73).

Em relação à filosofia kantiana é especialmente o apriorismo que foi colocado em questão pelos dois autores. Por exemplo, os conceitos de espaço e tempo como formas puras da sensibilidade, e as noções de causalidade e substância como conceitos puros do entendimento, já não podem ser concebidos como "a priori absolutos". Assim, Bachelard (1996) e Heisenberg (2007) põem em questão os limites de aplicação de determinados conceitos kantianos, pois, uma vez que se evidenciou que o saber científico se modifica em seu desenvolvimento histórico, uma noção nunca se encontrará absolutamente definida com precisão.

Heisenberg (2007) destaca que a geometria euclidiana, a lei de conservação da matéria, a lei da gravitação e a igualdade da ação e reação, são tratadas por Kant como a priori absolutos. Os conceitos a priori da filosofia kantiana já não podem pertencer diretamente à física contemporânea. "Nenhum físico estaria disposto a seguir Kant se o termo "a priori" for empregado no sentido absoluto que ele deu" (p. 80).

$O$ físico alemão também acusa Kant de manter certa conexão com o realismo ao realizar a distinção entre fenômeno e númeno. Ao manter a noção de númeno como aquilo que só pode ser pensado, e não perceptível, o filósofo de Königsberg estaria, de certo modo, dentro da problemática moderna da existência real ou não das coisas.

Bachelard (1970), por sua vez, ao apontar os limites do uso do conceito de númeno da filosofia kantiana, compreende que os objetos quânticos são eles mesmos númenos matemáticos, uma vez que esses objetos do conhecimento se estabelecem primeiramente como objetos do pensamento racional, eles são teórico-matemáticos, correspondendo a fórmulas algébricas universais e objetivas e que se realizam por meio da experiência técnica.

philosophy, the revolution in modern science, no capítulo "Development of philosophical ideas since Descartes in comparison with the new situation in teoria quântica".

14 Ver o exemplo dado por Bachelard acerca do átomo de hidrogênio em Le nouvel esprit scientifique, capítulo VI, seção IV.

VELANES, David. G. Bachelard e W. Heisenberg: o problema da linguagem na mecânica quântica. Griot : Revista de Filosofia, 
Para o físico alemão, os conceitos da teoria do conhecimento de Kant possuem apenas um campo limitado de aplicação, consistindo, eles mesmos, como uma verdade relativa ${ }^{15}$. Entretanto, afirma o autor que, embora se deva ser pensado nos limites precisos do uso das noções clássicas como parte da construção do pensamento humano do qual herdamos, é preciso compreender que esses conceitos constituem parte integral do método científico como base para todo trabalho científico. Aqui, pode-se notar a concepção de Heisenberg com relação à noção de complementaridade entre o saber do passado e o do presente.

A crítica mais contundente de Heisenberg (2007) é em relação ao conceito de causalidade como intrínseco ao método de investigação científica, pois, a lei de causalidade, é aplicável ao real da experiência ordinária, a qual se debruça a física clássica. Contudo, a lei de causa e efeito se revelou insustentável na compreensão objetiva acerca dos fenômenos atômicos. As relações de indeterminação tornaram impossível saber a causa dos fenômenos atômicos e extrair previsões exatas. ${ }^{16}$

A posição de Bachelard se revela mais radical, uma vez que tem como base sua noção de ruptura epistemológica. Bachelard não aceita que as noções sejam transplantadas diretamente de uma época a outra sem uma retificação discursiva. Essa posição bachelardiana diz respeito à sua concepção de recorrência histórica ${ }^{17}$, que implica em reconhecer os valores atuais dos conceitos para compreender seus limites de aplicação.

Além de apontar os limites dos conceitos filosóficos clássicos, como os de Kant, Bachelard pensa determinadas noções clássicas por meio de sua dialética da filosofia do não. ${ }^{18} \mathrm{O}$ nãosubstancialismo e o não-causalismo, por exemplo, são formas conceituais que permitem compreender a atualização desses conceitos, em relação às suas formas clássicas, mediante as novas experiências da ciência quântica.

Segundo Bachelard (1999), a física quântica se trata de uma física não-causal, pois a causalidade se encontra como um caso particular dentro de um campo mais amplo e complexo. Assim, o conceito de causalidade da filosofia kantiana deve ser pensado dentro de um racionalismo complexo e aberto, um não-kantismo, que leva em conta suas relações com o empirismo, isto é, não estabelece antagonismo com as ideias da filosofia empirista. Bachelard (1996) argumenta que "um empirismo sem leis claras, sem leis coordenadas, sem leis dedutivas não podem ser pensado nem ensinado; um racionalismo sem provas palpáveis, sem aplicação à realidade imediata não pode convencer plenamente" (p. 4-5).

Tais considerações de Bachelard e Heisenberg acerca das filosofias cartesiana e kantiana indicam que o problema da linguagem, na nova física, estende-se aos próprios fundamentos filosóficos desta ciência, isto é, aos conceitos da linguagem filosófica, e não somente aos conceitos científicos, empregados pelo pensamento moderno para a compreensão da natureza do saber científico. Como afirma Bachelard (1966), uma vez que ocorreu uma ruptura bastante clara entre saber comum e saber científico, na época contemporânea, já não é possível que ambos os tipos de conhecimento possam ter os mesmos fundamentos filosóficos.

\footnotetext{
${ }^{15}$ Em relação aos conceitos kantianos como verdades relativas ver também W. Heisenberg, A parte e o todo, cap X: “Mecânica quântica e filosofia kantiana (1930-1932)".

16 Acerca do princípio de incerteza ver Heisenberg (2007, p. 49). Pode-se conferir também Bachelard (1999, p. 126).

17 Acerca da noção bachelardiana de recorrência histórica é possível conferir G. Bachelard, L'activité rationaliste de la physique contemporaine, cap I: "Les récurrences historiques. Épistémologie et histoire des sciences. La dialectique onde-corpuscule dans son développement historique".

${ }^{18}$ Para uma compreensão da dialética bachelardiana se deve conferir G. Bachelard, La philosophie du non, cap VI: "La valeur synthétique de la "philosophie du non".
}

VELANES, David. G. Bachelard e W. Heisenberg: o problema da linguagem na mecânica quântica. Griot : Revista de Filosofia, 


\section{Considerações finais}

Bachelard e Heisenberg destacam bem o problema da linguagem na mecânica quântica, mas trazem soluções diferentes para a questão.

$O$ filósofo francês ressalta o perigo para a objetividade científica quando se recorre à aplicação dos conceitos científicos clássicos para a compreensão dos fenômenos atômicos. Também evidencia que os conceitos filosóficos se tornaram obsoletos em relação à natureza da nova física. Nesse sentido, Bachelard exige uma conscientização de cientistas e filósofos acerca do dinamismo das noções e dos obstáculos que podem ser gerados quando se toma o passado histórico sem uma análise crítica e recorrente. Além disso, ao radicalizar sua noção de ruptura epistemológica, ele compreende que a linguagem científica deve apenas se pautar nas matemáticas como característica fundamental das ciências do novo espírito científico, que se distanciou do senso comum e da linguagem da vida ordinária.

Heisenberg, embora evidencie que a linguagem conceitual das ciências tende a perder fecundidade explicativa no decurso da evolução do saber podendo gerar compreensões ambíguas acerca dos resultados nos experimentos em mecânica quântica, ao aceitar o princípio de complementaridade, propõe que os conceitos clássicos sejam utilizados para descrever os fenômenos quânticos, com a finalidade de tornar esses resultados compreensíveis a todos, uma vez que a mecânica dos quanta emergiu como um setor da física sem antecedentes históricos e, portanto, carente de um arcabouço conceitual que pudesse ser entendido por aqueles que não são físicos. Semelhante a Bachelard, o físico alemão também compreende que a linguagem filosófica perde sua aplicabilidade no decurso da história havendo a necessidade de atualização, mas, diferente do filósofo da ruptura, e ainda admitindo a complementaridade como princípio base de sua interpretação da física quântica, o físico alemão aceita que determinados conceitos, como aqueles da filosofia do conhecimento kantiana, possam ser relativizados para interpretar a natureza da nova física.

Ambos os autores concordam que as experiências técnicas introduzidas pela física quântica e novos objetos do conhecimento que emergiram com essa ciência evidenciaram os limites dos conceitos que tomam como base a vida cotidiana, mesmo aqueles mais refinados como os apresentados pela geometria euclidiana, pelo sistema newtoniano e pela filosofia kantiana, por exemplo. A nova física, uma vez que se distanciou do senso comum, implicou em mudanças fundamentais na relação do homem com a natureza à medida que esta deixa de ser o ponto de partida para entender a realidade cedendo lugar à matemática.

É possível dizer que as críticas dos dois autores ao pensamento moderno também diz respeito à concepção de que há um movimento do saber que progride do decurso da história. Este movimento do conhecimento estabelece novas experiências e novas teorias que evidenciam os limites dos conceitos de outrora e exige o processo de retificação, tal como a consciência da ambiguidade que podem prevalecer nas antigas noções como um problema para a objetividade científica. 


\section{Referências}

BACHELARD, Gaston. L'activité rationaliste de la physique contemporaine. Paris: PUF, 1965.

BACHELARD, Gaston. Essai sur la connaissance approchée. Paris: J. Vrin, 1986.

BACHELARD, Gaston. "Noumène et microphysique". In: Études. Paris: J. Vrin, 1970.

BACHELARD, Gaston. Le matérialisme rationnel. Paris: PUF, 1963.

BACHELARD, Gaston. Le nouvel esprit scientifique. Paris: PUF, 1999.

BACHELARD, Gaston. Le rationalisme appliqué. Paris: PUF, 1966.

BACHELARD, Gaston. Les intuitions atomistiques. Paris: J. Vrin, 1975.

BACHELARD, Gaston. La philosophie du non. Paris: PUF, 1996.

BACHELARD, Gaston. La formation de l'esprit scientifique. Paris: J. Vrin, 1993.

BACHELARD, Gaston. La valeur inductive de la relativité. Paris: J. Vrin, 2014.

BOHR, Niels. Física atômica e conhecimento humano. Rio de Janeiro: Contraponto, 1995.

CANGUILHEM, Georges. Études d'histoire et de philosophie des Sciences: concernant les vivants et la vie. Paris: Vrin, 1979.

CASSIDY, C. Uncertainty: the life and science of Werner Heisenberg. New York: W. H. Freeman, 1991.

FREIRE JR, Olival. “O silêncio do filósofo: a diversidade das influências das ideias de Louis de Broglie sobre o pensamento de Gaston Bachelard". In: SANT'ANNA, Catarina. (Org.). Para ler Gaston Bachelard: ciência e arte. Salvador: EDUFBA, 2010. p. 189-197.

FOUCAULT, Michel. A arqueologia do saber. Rio de Janeiro: Forense Universitária, 2008.

GUIMARÃES, Gustavo Bertoche. "Uma última ruptura: o silêncio epistemológico de Bachelard após 1953". Princípios - Revista de Filosofia. Natal, v. 25, n. 46, p. 9-27, 2018.

HEISENBERG, Werner. Physics and philosophy: the revolution in modern science. New York: Penguin Books, 2007.

HEISENBERG, Werner. La nature dans la physique contemporaine. Paris: Gallimard, 1962.

HEISENBERG, Werner. La física del núcleo atómico. Madrid: Revista de Occidente, 1954.

HEISENBERG, Werner. A parte e todo. Rio de Janeiro: Contraponto, 1996.

HEISENBERG, Werner. The physical principles of the quantum theory. Chicago/New York: University of Chicago/Dover, 1949.

HEISENBERG, Werner. "The development of the interpretation of the quantum theory". In: PAULI, W.; ROSENFELD, L. \& WEISSKOPF, V. (Ed.). Niels Bohr and the development of physics. Essays dedicated to Niels Bohr on the occasion of his seventieth birthday. London/New York: Pergammon/McGraw-Hill, 1955. p. 12-29.

LEITE, Anderson. SIMON, Samuel. "Werner Heisenberg e a Interpretação de Copenhague: a filosofia platônica e a consolidação da teoria quântica". Scientiae studia, São Paulo, v. 8, n. 2, p. 213-41, 2010.

PLANCK, Max. Autobiografia Científica e outros escritos. Rio de Janeiro: Contraponto, 2012.

VELANES, David. Gaston Bachelard e o progresso do saber. Rio de Janeiro: Multifoco, 2018.

Autor(a) para correspondência: David Velanes, Faculdade de Filosofia e Ciências Humanas. Estrada de São Lázaro, 197 - Federação, 40210-730, Salvador - BA, Bahia. dvelanes@gmail.com

VELANES, David. G. Bachelard e W. Heisenberg: o problema da linguagem na mecânica quântica. Griot : Revista de Filosofia, 